\title{
Gürültü Filtreleme Uygulamalarının Medikal Görüntüler Üzerindeki Performanslarının Değerlendirilmesi
}

\author{
Furkan Kutan ${ }^{1 *}$, Ömer Aynur ${ }^{2+}$ \\ ${ }^{1}$ SBİ Bilişim A.Ş. Ankara, Türkiye (ORCID: 0000-0001-8219-3640) \\ ${ }^{2}$ SBİ Bilişim A.Ş. Ankara, Türkiye (ORCID: 0000-0002-5808-6367)
}

(Bu yayın 26-27 Haziran 2020 tarihinde HORA-2020 kongresinde sözlü olarak sunulmuştur.)

(DOI: 10.31590/ejosat.779957)

ATIF/REFERENCE: Kutan, F. \& Aynur, Ö. (2020). Gürültü Filtreleme Uygulamalarının Medikal Görüntüler Üzerindeki Performanslarının Değerlendirilmesi. Avrupa Bilim ve Teknoloji Dergisi, (Special Issue), 265-271.

$\ddot{O} \mathbf{z}$

Beyin anevrizmaları, beyine giden serebrovasküler kan damarları duvarlarının zayıflığından kaynaklanan damarlardaki şişmelerdir. Bu şişmeler, gereğinden fazla zayıflayan damar duvarlarının yırtılmasına sebep olabilir. Bunun sonucunda çok ciddi hastalıklar, sakatlıklar ve hatta ölümler meydana gelebilir. Beyin anevrizmalarının tedavi edilmesindeki en önemli etken hastalığın erken tespit edilmesidir. Beyin anevrizmalarının ilk aşamalarında, baloncukların küçük boyutlara sahip olmasından dolayı erken teşhis imkânı zorlaşmaktadır. Tecrübeli ve yetenekli radyologlar dahi erken aşamadaki anevrizmaları tespit edilmesi noktasında yetersiz kalabilmektedirler. Bu sebepten dolayı beyin anevrizmalarının tespitinde ve erken teşhisinde bilgisayar sistemlerinden faydalanılmaktadır. Beyin anevrizmaları tespit etmek için kullanılan MR görüntüleri; CT(Computer Tomography), MRA(Magnetic Resonance Angiography) ve DSA(Digital Subtraction Tomography) şeklindedir.

CTA ve MRA anevrizma tespitinde en çok kullanılan tekniklerdir. Ancak her iki teknikte de çok küçük boyuttaki beyin anevrizmalarının tespitinde yetersiz olabilmektedir. Bu yetersizlik beyin anevrizması tedavilerinde erken teşhis imkanını ortadan kaldırmaktadır.

CTA ve MRA tekniklerinin aksine DSA görüntüleri beyin anevrizmalarının tespitinde daha başarılıdır. Özellikle hastalığın erken teşhisinde DSA teknikleri altın standart olarak kabul edilmektedir.

Bilgisayar sistemlerinden faydalanılarak beyin anevrizmalarının tespit ve erken teşhis başarılarını artırmak için yukarıda adı geçen MR (Magnetic Resonance) tekniklerindeki görüntüler analiz edilmektedir. Beyin anevrizmaları tespitinde kullanılan 2 farklı analiz yöntemi vardır. Bunlardan ilki, görüntü işleme tekniklerini kullanarak MR resimlerinden anlamlı karakter bilgilerini çıkartarak yapılan çalışmalardır. İkinci yöntem ise derin öğrenme ve yapay sinir ağlarını kullanarak MR resimlerinin karakter bilgilerini otomatik olarak çıkartarak yapılan çalışmalardır. MR görüntüleri üzerinden analiz yapılmadan önce bu görüntülere bazı ön işlemlerin uygulanması gerekmektedir. Bunun nedeni MR görüntüleri cihazının doğası ve içindeki devrelerin yapısından kaynaklı gürültü bileşenleri içermektedir. Bu incelemede MR görüntülerdeki anlamlı kısımları koruyarak, gürültü işlemlerini giderebilecek filtre çeşitleri incelenmiş ve uygulanmıştır.

Anahtar Kelimeler: Gürültü filtreleme, Manyetik Rezonan Görüntüleme, Görüntü İşleme, Anevrizma

\section{Evaluation of Performance of Noise Filtering Applications on Medical Images}

\begin{abstract}
A brain aneurysm is cerebrovascular disorder which is caused by weakness in blood vessels. This disorder can result in immediate or delayed morbidity and mortality. Brain aneurysms are present in about 2 to 3 percent of the population. In the USA, the estimated number of unruptured brain aneurysms is more than 6 million.
\end{abstract}

\footnotetext{
* Sorumlu Yazar: SBİ Bilişim A.Ş. Yapay Zekâ Mühendisi, Ankara, Türkiye, (ORCID: 0000-0001-8219-3640), fkutan@sbibilisim.com.tr

${ }^{\dagger}$ Sorumlu Yazar: SBİ Bilişim A.Ş. Yapay Zekâ Mühendisi, Ankara, Türkiye, (ORCID: 0000-0002-5808-6367), oaynur@sbibilisim.com.tr
} 
The most crucial factor for clinical treatment of brain aneurysms is early diagnosis. Early diagnosis is a rather difficult procedure. Because of aneurysm's tiny size at an early stage, even experienced radiologists can miss the detection of some aneurysms. Regarding this reason, CAD (Computer-Aided Diagnosis) systems are needed to help radiologists to have much more reliable detections.

There are three most used medical imaging techniques used for brain aneurysm detection. These are CTA (Computed Tomography Angiography), MRA (Magnetic Resonance Angiography) and DSA (Digital Subtraction Angiography).

CTA and MRA are widely known imaging techniques used for general detection. However, these techniques generally fail to detect small aneurysms for early diagnosis. On the other hand, DSA imaging technique is said to be the 'golden standard' for early diagnosis in literature.

All these imaging techniques mentioned above can be used to built CAD systems for making detection more reliable.

CAD systems for aneurysm detection can be built using two methods. The first one is using DIP (Digital Imaging Processing) techniques and extracting hand-crafted features for classical machine learning algorithms. The second one is using deep neural networks and feeding networks directly full of images as inputs. In this technique, there is no feature engineering for feature extraction. Deep neural networks learn appropriate features on his own.

Before using two methods mentioned just above, it's needed to operate some preprocessing techniques on input images. This is because MR (Magnetic Resonance) machines naturally put some noises on output images. In this paper, image filtering techniques are tested and applied in order to get rid of the impact that is caused by the noises on the image by preserving meaningful pixels and features of the images.

Anahtar Kelimeler: Denoising, Magnetic Resonance Imaging, Image Processing, Aneurysm

\section{Giriş}

Resim ve dijital sinyallerdeki gürültü; görüntüler üzerinde ortaya çıkan leke, bozukluk gibi istenmeyen işaretlerdir ve görüntünün kalitesini düşürdüğü gibi görüntüdeki anlamlı kısımların da fark edilmesine engel olabilmektedir. Sonuç olarak görüntünün analiz edilmesini olumsuz etkilemektedir. Bu gürültüler yapay zekâ modelleri için de hesaplama gücünü (Computational Power) artırabileceği gibi modelin daha geç global minimuma ulaşmasına sebebiyet verip modelin başarısını olumsuz yönde etkileyebilmektedir.

Medikal görüntülerde gürültüler genellikle ortamın veya görüntüyü çeken cihazın ideal olmamasından kaynaklandığı gibi görüntüyü çeken radyologdan da kaynaklanabilir. Bu incelemede cihazın ideal olmamasından kaynaklanan gürültülerin giderilmesine yönelik çalışmalar yapılmıştır. Literatürde görüntüler üzerindeki gürültüleri gidermek için çeşitli algoritmalar önerilmiştir fakat bu algoritmalar her görüntü için istenilen sonuçları vermemektedir. Bu yüzden algoritma seçimi yapılırken görüntünün yapısı ve karakterine uygun olmas1 gerekmektedir. (Solomon,2011)

Medikal görüntülere filtreleri uygularken dikkat edilmesi gereken en önemli kriter; görüntünün içerisindeki anlamlı bölgeleri kaybetmeyerek, görüntü üzerinde var olan bölgelerdeki gürültüyü gidermektir. Buna bağlı olarak da MR görüntülerindeki gürültüyü gidermek için çeşitli filtreler önerilmektir. Literatürde lineer filtreler (McVeigh ve ark.,1985), anizotropik difüzyon (Perona ve ark.,1990), yerel olmayan ortalamalar (Buades ve ark.,2005), bilateral filter ve trilateral filtreler (Hamarneh ve ark.,2007), iş birlikçi filtreler (Dabov ve ark.,2007), median filtre (Wang ve Zhang,1999) gibi lineer olmayan filtreler ve dalgacık eşikleme (Chang ve ark.,2000) gibi methodlar görüntülerdeki gürültüyü gidermek için kullanılmaktadır.

Bu çalışmada Mr görüntülerindeki gürültüleri gidermek için görüntülere 3 farklı filtre uygulanmış ve bu filtrelerinde başarı performanslarını değerlendirmek için PSNR (Peak Signal to Noisy Rate) ve SSIM (Structural Similarity Index) ölçüm metrikleri seçilmiştir. PSNR ölçüm metriği orijinal görüntü üzerine gürültü eklediğimiz görüntüleri değerlendirmede, SSIM metriği ise doğrudan orijinal görüntülere filtre uygulanmasıyla oluşan sonucu değerlendirmede kullanılmıştır. Çalışmaya sadece en iyi performans sonucu veren filtrelere ait görüntüler eklenmiştir, diğer sonuç görüntülerinin başarı derecesi ise tablolar ile gösterilmektedir.

\section{Materyal ve Metot}

\subsection{Gürültü Gidermede Kullanılacak Filtreler}

Bu incelemede MR görüntülerindeki gürültüleri filtreleme de Bilateral, NLM (Non Local Means) ve BM3D (Block Matching and 3D) filtreler kullanılmıştır.

\subsubsection{Bilateral Filtre:}

Bilateral filtre, görüntüler için lineer olmayan uygulandığında kenarları koruyucu ve gürültü azaltıcı özellik gösteren bir yumuşatma filtresidir. Çalışma prensibindeki temel mantık görüntü içerisindeki her bir pikselin yoğunluğu, komşu piksel değerlerinin ortalama yoğunluk değerleri hesaplanıp değiştirilmesiyle oluşmaktadır. Buradaki değiştirilen her bir pikselin yoğunluğu sadece pikseller arasındaki Öklid mesafesine bağlı değildir. Aynı zamanda görüntünün içerisindeki derinlik mesafesi, renk yoğunluğu gibi farklı özelliklere bağlı olarak da değişmekte ve bu sayede görüntüde anlamlı noktaların korunması sağlanmaktadır. (Tomasi ve Manduchi,1998)

Bilateral filtrenin temel matematiksel gösterimi Eşitlik 1 ile ifade edilmektedir.

I filtered $(\mathrm{x})=\frac{1}{W_{p}} \sum_{x_{i} \in \Omega} I\left(x_{i}\right) f_{r}\left(\left\|I\left(x_{i}\right)-I(x)\right\|\right) g_{S}\left(\left\|x_{i}-x\right\|\right) \quad 1$

$I^{\text {filtered }}(\mathrm{x})=$ Filtre sonrası oluşan görüntü 
I =Gürültü içeren giriş görüntüsü

$\mathrm{X}=$ Filtrenin uygulanacağı piksellerin koordinatları

$\Omega=$ Filtrenin uygulanacağı pikseli merkeze alan pencere $\mathrm{x}_{\mathrm{i}} \in \Omega$

$\mathrm{f}_{\mathrm{r}}=$ Pikseller arasındaki farklılıkları yumuşatmak için kullanılan fonksiyon

$\mathrm{g}_{\mathrm{s}}=$ Koordinatlar arasındaki farklılıkları yumuşatmak için kullanılan mekânsal fonksiyon

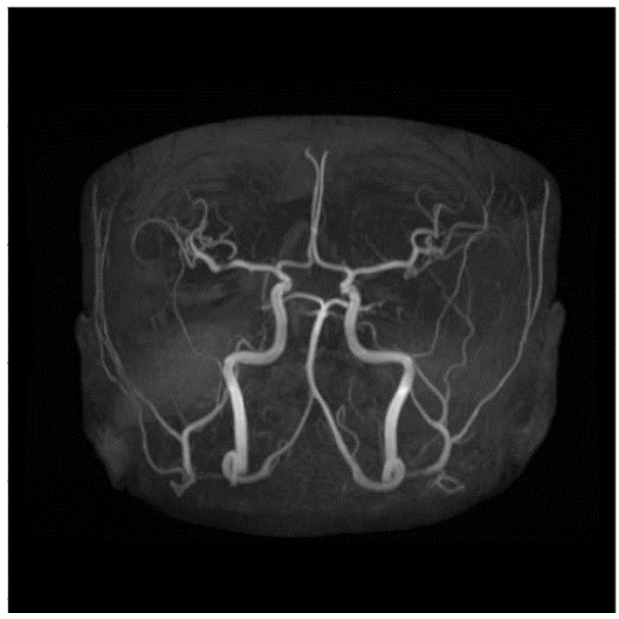

Şekil 1.1.a

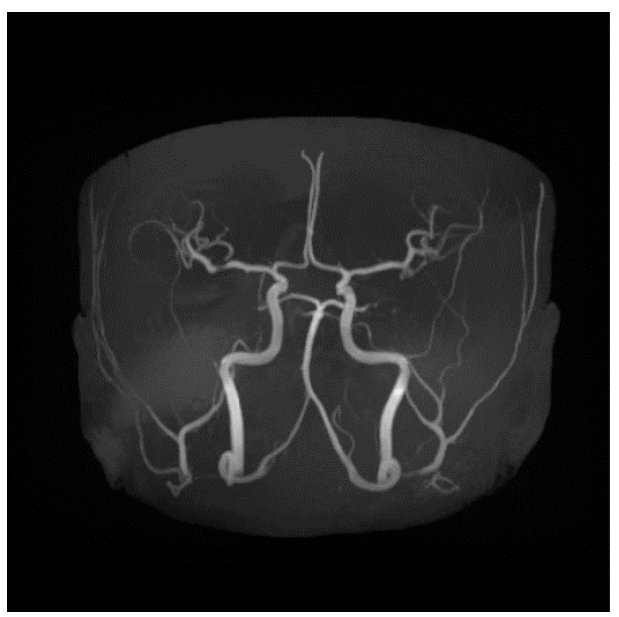

Şekil 1.1.b

Şekil 1.1.a'da gösterilen görüntü üstüne gürültü eklenmeyen, sadece MR cihazının doğasından kaynaklı oluşan gürültüleri içermektedir. Şekil 1.1.b ise bu görüntünün Bilateral filtresi uyguladıktan sonra oluşan çıkış görüntüsünü göstermektedir.

\subsubsection{Non Local Means(NLM) Filtre:}

NLM filtre, görüntü işlemede görüntüler üzerindeki gürültüleri azaltmak için kullanılan bir görüntüyü yumuşatma filtresidir. Normalde yerel düzgünleştirme (local smoothing) filtreleri görüntü üzerindeki gürültüleri azaltırken önemli doku ve detayların (kenar köşe vb.) kaybedilmesine sebep olmaktadırlar. Çünkü görüntündeki anlamlı noktalar fonksiyonel yönlerden gürültü gibi davranabilir. Fakat burada diğer yerel ortalama filtrelerinden farklı olarak görüntü içerisindeki her bir pikselin komşu piksel değerlerine göre ortalaması alınırken ana piksele benzerliğine bağlı olarak ağılıklandırılmaktadır. Bu sayede filtreleme sonrası görüntü daha net ve daha az anlamlı bölge kaybı ile sonuçlanır. (Buades ve ark.,2005)

NLM filtresinin temel matematiksel gösterimi Eşitlik 2 ile ifade edilmektedir.

I filtered $(\mathrm{x})=\sum_{q \in \mathrm{X}} W(p, q) X(q)$

I filtered $(\mathrm{x})=$ Filtrelenmiş görüntü

$\mathrm{X}=\mathrm{Gürültü} \mathrm{içeren} \mathrm{giriş} \mathrm{görüntüsü}$

$\mathrm{p}=$ Filtre uygulanacak piksel

$\mathrm{q}=$ Filtre uygulanacak piksele komşu piksel

$\mathrm{W}(\mathrm{p}, \mathrm{q})=$ Pikseller arasındaki benzerliği gösteren ağırlık matrisi

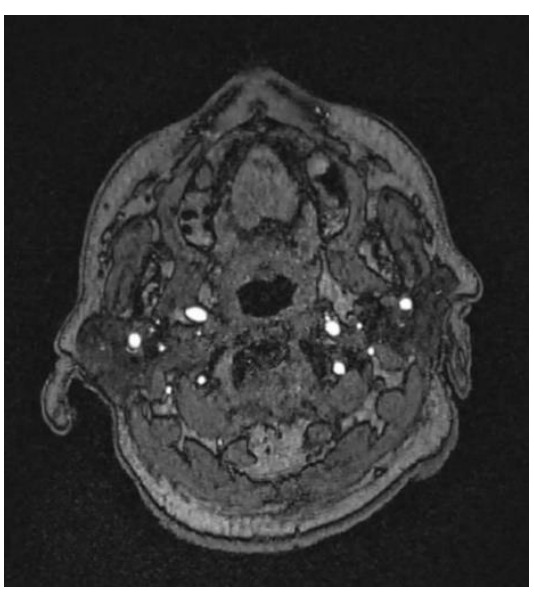

Şekil 2.1.a

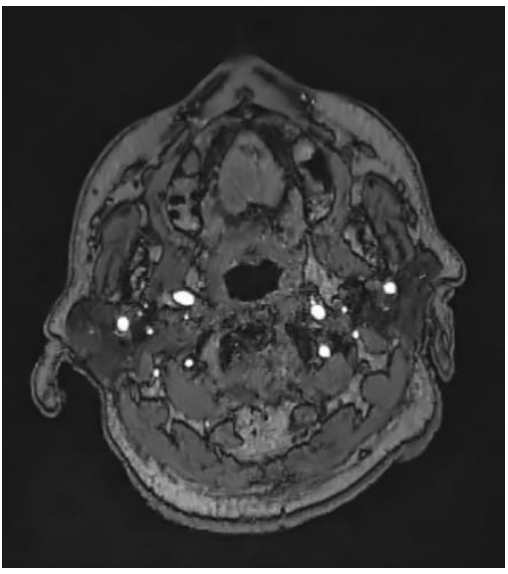

Şekil 2.1.b 
Şekil 2.1.a üstüne gürültü eklenmeyen orijinal MR görüntüsünün farklı bir kesitten görünüşünü göstermektedir. İçerisinde sadece MR cihazının doğasından kaynaklı oluşan gürültüleri içermektedir. Şekil 2.1.b ise bu görüntünün NLM filtresi uyguladıktan sonra oluşan çıkış görüntüsünü göstermektedir.

\subsubsection{BM3D(Block Matching and 3D) Filtre:}

Blok eşleme ve $3 \mathrm{~d}$ filtreleme, görüntülerdeki gürültüleri (parazitleri vb.) gidermek amaciyla kullanılan bir filtredir. Bu filtre literatürde iş birlikçi filtre olarak da adlandırılır. Temelde filtrenin çalışması 4 aşamada gerçekleşir. İlk aşamada görüntüdeki benzer parçalar bloklar halinde tutularak kendi aralarında 3 boyutlu şekilde gruplandırllır. İkinci ve üçüncü aşamada bu gruplar Wiener filtreleme tekniğine bağlı olarak 3 boyutlu doğrusal dönüşüme tabi tutulur ve spektrum domainindeki katsayılar Wiener tekniğine uygun olarak küçültülür. Son aşamada ise 3 boyutlu doğrusal dönüşümün tersi alınarak tekrardan görüntü parçaları elde edilir ve bu parçalar orijinal pozisyonlarına getirilir. Görüntü üzerindeki bu parçaların orijinal pozisyonlarına getirilirken üst üste geldiği durumlarda ortalama değerleri alınır. (Marc Lebrun ,2012)

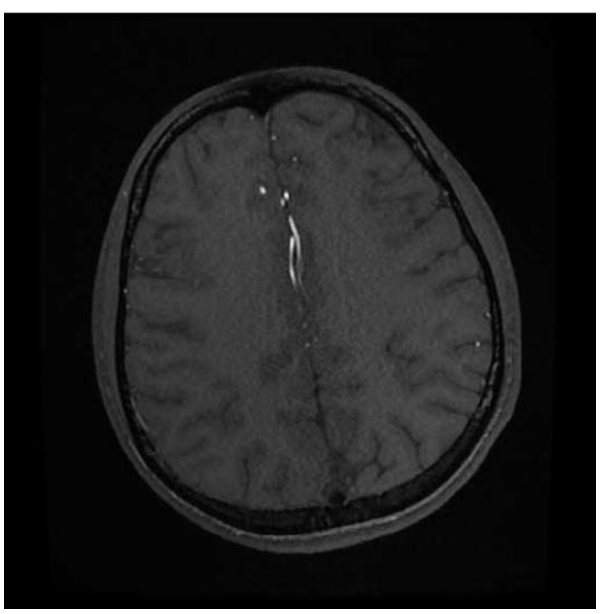

Şekil 3.1.a

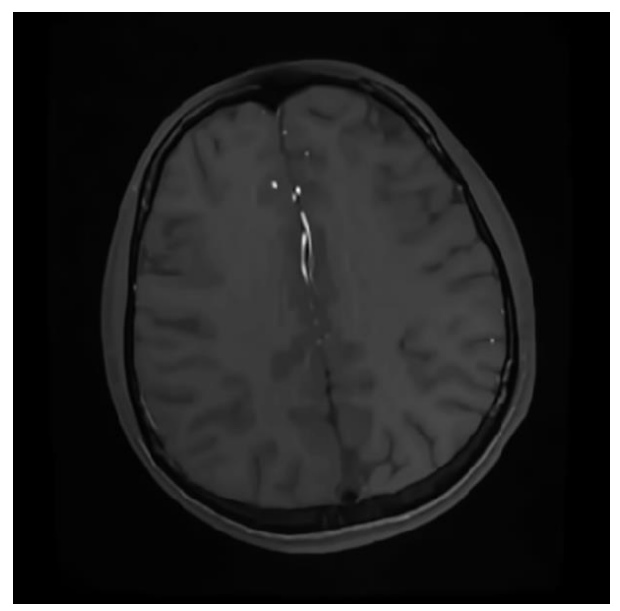

Şekil 3.1.b

Şekil 3.1.a üstüne gürültü eklenmeyen orijinal MR görüntüsünü göstermektedir. İçerisinde sadece MR cihazının doğasından kaynaklı oluşan gürültüleri içermektedir. Şekil 3.1.b ise bu görüntünün BM3D filtresini uyguladıktan sonra oluşan çıkış görüntüsünü göstermektedir.

Aşağıdaki resimlerde ise PSNR ölçüm metriğini kullanabilmek için sırasıyla yukarıda gösterilen orijinal görüntülere Gausian gürültüsünün eklenip daha sonrasında BM3D filtresinden geçirilerek çıkış görüntüleri gösterilmektedir.

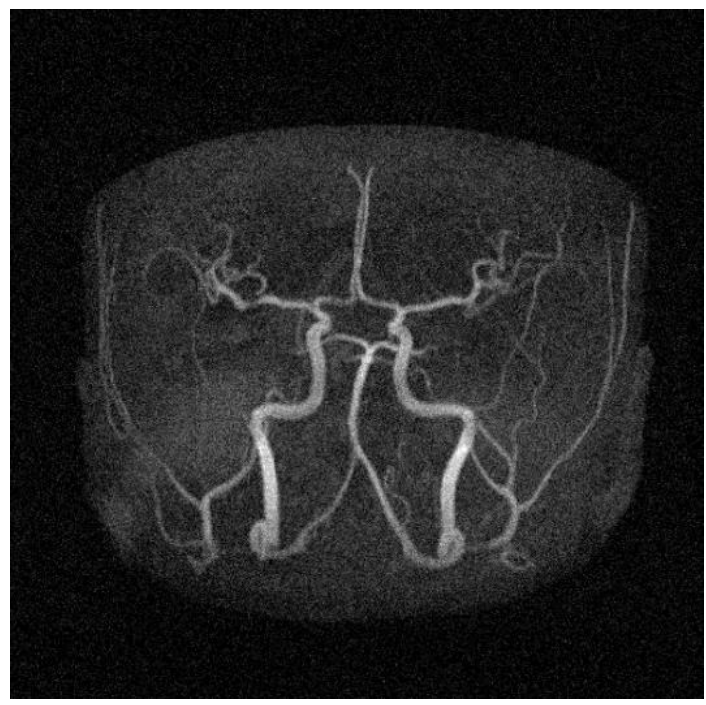

Şekil 4.1.a

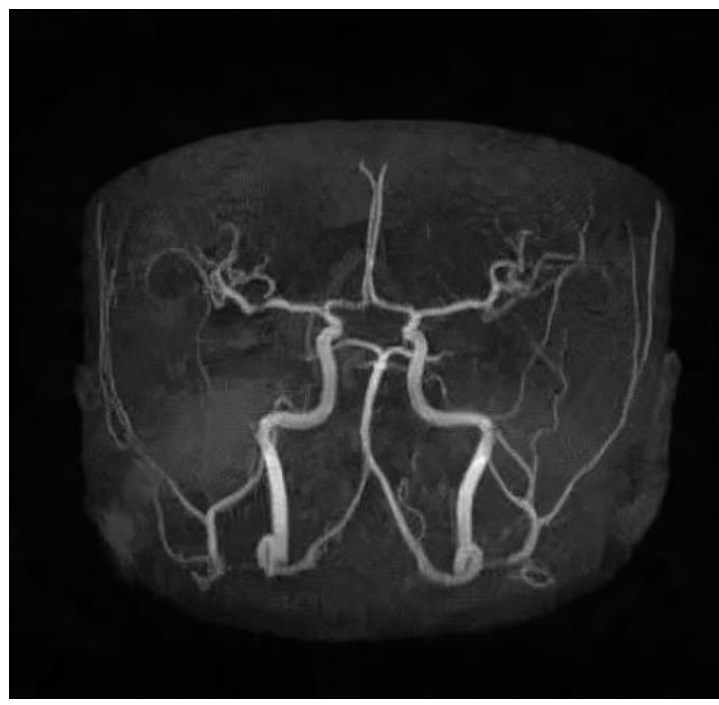

Şekil 4.1.b 


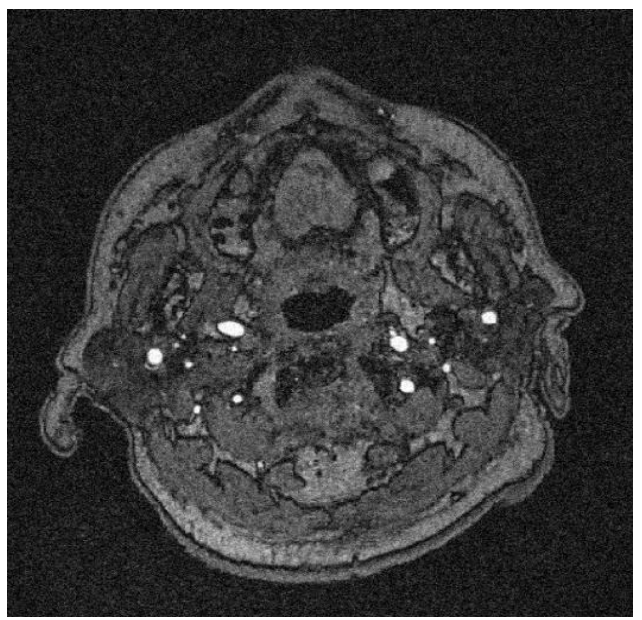

Şekil 4.2.a

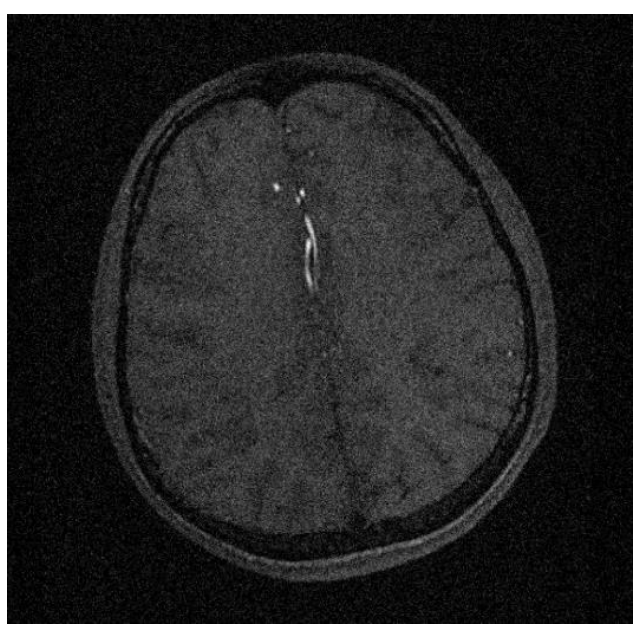

Şekil 4.3.a

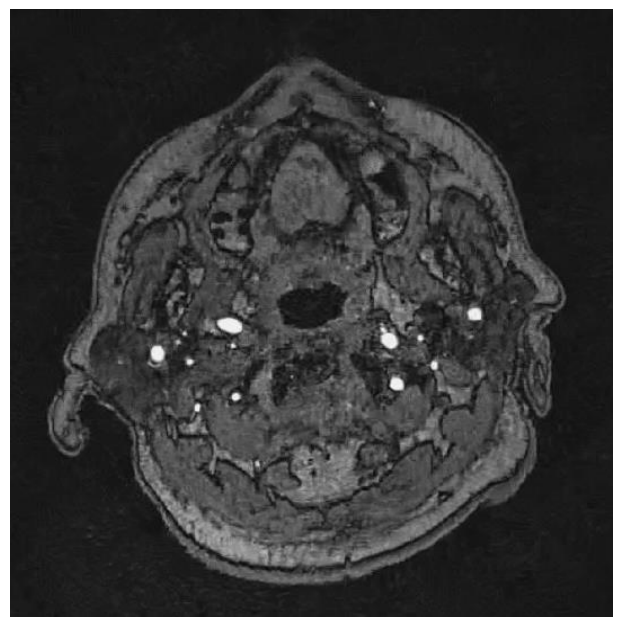

Şekil4.2.b

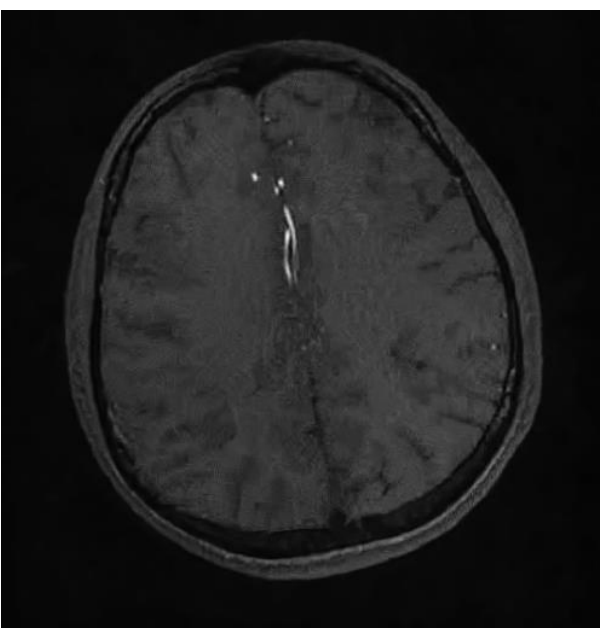

Şekil 4.3.b

\subsection{Performans Değerlendirme}

Bu çalışmada görüntüler üzerindeki gürülttüyü gidermede kullanılan filtrelerin performanslarını ölçmek için PSNR ve SSIM ölçüm metrikleri kullanılmıştır.

\subsubsection{PSNR (Peak Signal to Noise Ratio)}

PSNR görüntüler üzerindeki filtrelerin performansını ölçmek için literatürde sıklıkla kullanılmaktadır. Bu ölçüm metriği işlenmiş görüntü ile orijinal görüntü arasındaki iyileştirmenin ölçütünü veren kalite ölçüm metriğidir. PSNR değeri db (Decibell) birimiyle ölçülür ve bu değerin yüksek olması elde edilen görüntü kalitesinin de yüksek olduğu anlamına gelmektedir. Çalışma prensibi orijinal görüntü ile filtrelenmiş görüntü arasındaki piksel yoğunluklarının karşıllaştırılmasına dayanır, eğer ki piksel yoğunlukları arasındaki fark fazla ise PSNR düşük db değeri verirken yoğunluk farklılıklarının az olduğu durumlarda ise bu db değeri artar. (Hore ve ark.,2010)

PSNR ölçüm metriğinin temel matematiksel gösterimi Eşitlik 3 ve 4 ile ifade edilmektedir.

$$
\begin{aligned}
\mathrm{MSE} & =\frac{\sum_{i=1}^{N} \sum_{j=1}^{M}\|F(i, j)-G(i, j)\|^{2}}{N M} 3 \\
\mathrm{PSNR} & =20 \log _{10} \frac{R}{\sqrt{M S E}}
\end{aligned}
$$

MSE $=$ Ortalama hata karesi

$\mathrm{F}=$ Orijinal görüntü

$\mathrm{G}=$ Filtre sonrası çıkış görüntüsü

$\mathrm{M}=$ Görüntüdeki satır sayısı

$\mathrm{N}=$ Görüntüdeki sütün sayıs1

$\mathrm{R}=$ Maksimum görüntü yoğunluk değeri 


\subsubsection{SSIM (Structural Similartiy Index)}

SSIM (Structural Similarity Index), görüntülerin birbirine benzerlik derecesini ölçmek için kullanılan bir metriktir. PSNR ve MSE metrikleri insan göz algısına uymadı̆̆ından ötürü SSIM tasarlanmıştır. Diğer iki metrikten farklı olarak SSIM görüntüdeki bozulmayı yapısal bilgideki algılanan değişiklik olarak ele alır. Bu sayede yapısal bilgi uzamsal olarak yakın piksellerdeki bağımlılığın daha güçlü olduğunu söyler. $\mathrm{Bu}$ bağımlılıklarda görüntü içerisinde bulunan nesnelerin yapıları hakkındaki bilgileri içerir. SSIM metriğini uygulanabilmesi için referans bir görüntü gereklidir daha sonrasında filtrelenmiş görüntü bu referans görüntüsü ile karşılaştırılarak SSIM skoru elde edilmektedir. (Wang ve ark.,2004)

SSIM ölçüm metriğinin temel matematiksel gösterimi Eşitlik 5 ile ifade edilmektedir.

$$
\begin{aligned}
& \operatorname{SSIM}(\mathrm{x}, \mathrm{y})=\frac{\left(2 \mu_{x} \mu_{y}+c 1\right)\left(2 \sigma_{x y}+c 2\right)}{\left(\mu_{x}^{2}+\mu_{y}^{2}+c 1\right)\left(\sigma_{x}^{2}+\sigma_{y}^{2}+c 2\right)} \\
& \mathrm{x}, \mathrm{y}=\mathrm{NXN} \text { boyutundaki görüntüler } \\
& \mu \mathrm{x}=\mathrm{x} \text { 'in ortalaması } \\
& \mu \mathrm{y}=\mathrm{y} \text { 'nin ortalaması } \\
& \sigma 2 \mathrm{x}=\mathrm{x} \text { 'in varyans1 } \\
& \sigma 2 \mathrm{y}=\mathrm{y} \text { 'nin varyans1 } \\
& \sigma \mathrm{xy}=\mathrm{x} \text { ve y'nin kovaryansı } \\
& \mathrm{L}=\text { Piksellerin alabileceği maksimum değerlik } \\
& \mathrm{K} 1=0.01 \text { ve } \mathrm{K} 2=0.03 \text { varsayılan sabit değerlere sahiptirler. Ana formülde paydanın 0'a yaklaşmasını önlemek için kullanıllır. } \\
& \mathrm{C} 1=(\mathrm{K} 1 \mathrm{~L}) 2 \text { ve } \mathrm{C} 2=(\mathrm{K} 2 \mathrm{~L}) 2
\end{aligned}
$$

SSIM skoru -1 ile 1 arasında değer alır eğer ki iki görüntü aynı ise 1 değerliğini almaktadır. Dolayısıyla SSIM skoru 1'e ne kadar yakınsa filtre uygulandıktan sonra yapısal olarak ana görüntüye sonucun o kadar yakın olduğu anlamına gelmektedir.

\section{Araştırma Sonuçları ve Tartışma}

\subsection{Tartışma}

Çalışmada kullanılan filtreler sayesinde görüntüler üzerindeki gürültüler gözle fark edilebilecek kadar azaltılmıştır. Dolayısıyla bu durum görüntü üzerinde çeşitli görüntü işleme tekniklerinin uygulanıp görüntüler üzerindeki anlamlı bölgelerin çıkartılmasını kolaylaştıracaktır. Ek olarak bu durum yapay zekâ modelleri içinde modelin daha hızlı başarıya ulaşmasını sağlayacaktır.

\section{Sonuç}

$\mathrm{Bu}$ çalışmada MR görüntülerinde gürültüleri gidermek için kullanılan filtrelerin, tüm resimler için en iyi sonucu veren baskın bir algoritmanın olmadığı ve PSNR ya da SSI skoru açısından net bir fark olmadığı gözlemlenmiştir. Yapılan çalışmada başarı ve yüksek performans için filtrelerin aldığı giriş parametrelerinin ve görüntünün karakteristiğinin sonuç üzerinde büyük etkilerinin olduğu da gözlemlenmiş̧ir.

Aşağıdaki tablolar çalışma içerisindeki görüntülere ait her bir filtre için PSNR ve SSI skorlarını göstermektedir. Şekilde gösterilen Tablo 1'de orijinal görüntülere doğrudan filtreler uygulanarak elde edilen sonuç performanslarının SSI skorlarına göre karşılaştırılmasını göstermektedir. Tablo 2'de ise orijinal görüntülere gürültü eklenip filtre uygulanmasıyla elde edilen sonuç performanslarının PSNR skorlarına göre karşılaştırılmasını göstermektedir.

Tablo 1. Orijinal Görüntü Filtre Sonrası SSI Skorları

\begin{tabular}{|l|l|l|l|}
\hline Orjinal Görüntü & $\begin{array}{c}\text { Bilateral SSI } \\
\text { Skoru }\end{array}$ & Non Local Mean SSI Skoru & BM3D SSI Skor \\
\hline Şekil 1.1.a & 0.9509 & 0.9409 & 0.9487 \\
\hline Şekil 2.1.a & 0.8783 & 0.9186 & 0.9065 \\
\hline Şekil 3.1.a & 0.9223 & 0.9240 & 0.9443 \\
\hline
\end{tabular}


Tablo 2. Gürültü Uygulanan Görüntülerin Filtre Sonrası PSNR Skorları

\begin{tabular}{|c|l|l|c|c|c|}
\hline Orijinal Görüntü & $\begin{array}{l}\text { Gürülttülü } \\
\text { Görüntü }\end{array}$ & $\begin{array}{l}\text { Gürülttülü } \\
\text { Görüntü PSNR } \\
\text { Skoru(dB) }\end{array}$ & $\begin{array}{c}\text { Bilateral } \\
\text { PSNR } \\
\text { Skoru(dB) }\end{array}$ & $\begin{array}{c}\text { Non Local } \\
\text { Mean PSNR } \\
\text { Skoru(dB) }\end{array}$ & $\begin{array}{c}\text { BM3D } \\
\text { PSNR Skoru } \\
\text { (dB) }\end{array}$ \\
\hline Şekil 1.1.a & Şekil 4.1.a & 23.58 & 30.18 & 30.65 & 32.18 \\
\hline Şekil 2.1.a & Şekil 4.2.a & 23.68 & 27.67 & 30.03 & 32.84 \\
\hline Şekil 3.1.a & Şekil 4.3.a & 22.58 & 26.84 & 28.86 & 30.99 \\
\hline
\end{tabular}

Bilateral filtresinde filtrenin uygulanacağı piksel için bakılacak komşu pixel uzaklığı için çap 40, sigmacolor ve sigmaspace parametleri 30 seçilmiştir. Çapın az seçilmesi MR görüntüleri için gürültüleri silip bulanıklılığı artırırken fazla seçilmesi belirli derecede görüntünün netliğini artırmakta fakat içerisinde gürültü bileşeni barındırmaktadır. Ek olarak sigmacolor ve sigma space parametreleri ise komşulukdaki piksellere bakılırken uzaklığı ayarlamaya yaramaktadır. Dolayısıyla bu parametrelerin yüksek oluşu komşuluk içerisindeki daha uzaklıktaki piksellerin filtrelenecek pixele etki ediceği anlamına gelmektedir. Bu durum da görüntülerin bulanıklı̆̆ını artırmaktadır.

NLM filtresinde $\mathrm{h}$ parametresi filtre kuvvetini belirlemede kullanılmaktadır. Bu çalışmada h parametrisinin değeri 7 olarak belirlenmiştir. h parametre değerinin artması, görüntüdeki gürültüleri muazzam derecede azaltırken kenar köşe gibi özelliklerin korunmasına engel olup detayların kaybedilmesiyle sonuçlanır ve görüntüyü bulanıklaştırır. Bu parametrenin azaltılması ise kenar köşeleri koruduğu gibi bazı gürültüleride içerisinde barındırır. Ek olarak templatewindowsize ve searchwindowsize parametre sırasıyla 11 ve 21 olarak seçilmiştir. Bu iki parametre NLM filtresinde komşu pixellerin ağırlıklarını hesaplamada kullanılır. Belirtilen parametrelerin fazla artırılması gürültünün kaldıramasını azaltmaktadır.

BM3D filtresi temelde sigma_psd ve stage_arg olmak üzere 2 farklı parametre değeri içermektedir. Sigma_psd parametresi gürültünün standart sapması anlamına gelmektedir. State_arg parametresi ise görüntüye hard thresholding metodunun tek başına mı yoksa hard thresholding ve Wiener filtreleme metodunun beraber mi uygulanacağını belirlemektedir. Bu çalışmada sigma_psd parametresi 0.1 değerinde state_arg parametresi ise All_Stages olarak seçilmiştir. Sonucunda hem hard thresholding hem de Wiener filtresi birlikte uygulanmıştır. Sigma_psd parametre değerinin artırılması ve state_arg için sadece hard thresholding seçilmesi görüntüdeki gürültüleri azaltırken görüntünün bulaknıklaşmasına sebep olmaktadırlar, sigma_psd parametresinin azaltılması ve state_arg parametresinin All_stage seçimi ise gürültünün kaldırılmasını azaltmaktadır.

\section{Kaynakça}

1. Solomon, C., 2011, Fundamentals of Digital İmage Processing, ISBN 978-0-470-84472-4, Wiley-Blackwell, UK

2. McVeigh E.R., Henkelman R.M., Bronskill M.J. "Noise and filtration in magnetic resonance imaging", Med. Phys. 12, 586-591, 1985.

3. Perona P. and Malik J. "Scale-space and edge detection using anisotropic diffusion", IEEE Trans. Pattern Anal. Mach. Intell. 12, 629-639, 1990.

4. Buades A, Coll B and Morel J.M. 2005. A non local algorithm for image denoising. IEEE Int. Conf. On Computer Vision and Pattern Recognition (CPVR) 2, 60-65.

5. Hamarneh G. and Hradsky J. "Bilateral filtering of diffusion tensor magnetic resonance images", IEEE Trans. Image Process. 16, 1723-1730, 2007.

6. K. Dabov, A. Foi, V. Katkovnik, and K. Egiazarian, "Image denoising by sparse 3D transform-domain collaborative filtering,” IEEE Trans Image Process., vol. 16, no. 8, pp. 2080-2095, August 2007.

7. Z. Wang, D. Zhang, "Progressive switching median filter for the removal of impulse noise from highly corrupted images", IEEE Transactions on Circuits and Systems, vol. 46, Issue 1, pp 78-80, Jan 1999

8. S. G. Chang, B. Yu, and M. Vetterli, "Adaptive wavelet thresholdingfor image denoising and compression," IEEE Trans. Image Process., vol. 9, no. 9, pp. 1532--1546, Sep. 2000.

9. C. Tomasi and R. Manduchi, "Bilateral filtering for gray and color images," Proc. Int. Conf. Computer Vision, 1998, pp. 839-846

10. Marc Lebrun An Analysis and Implementation of the BM3D Image Denoising Method 2012

11. Hore, A., Djemel Z., 2010, Image quality metrics: PSNR vs. SSIM, 2010 International Conference on Pattern Recognition, DOI 10.1109/ICPR.2010.579

12. Z. Wang, A.C. Bovik, H.R. Sheikh, E.P. Simoncelli, Image quality assessment: from error visibility to structural similarity, IEEE Transactions on Image Processing 13 (4) (2004) 600-612.

13. Zhang M. and Gunturk B.K.,"Multiresolution Bilateral Filtering for Image Denoising", IEEE Transactions on Image Processing, 17 (12), 2324-2333, 2008.

14. Wyatt M.G (1999) Aneurysmal disease. In: Davies A.H, editor. Vascular Surgery Highlights 1998-1999. Oxford: Health Press. pp. $41-48$. 